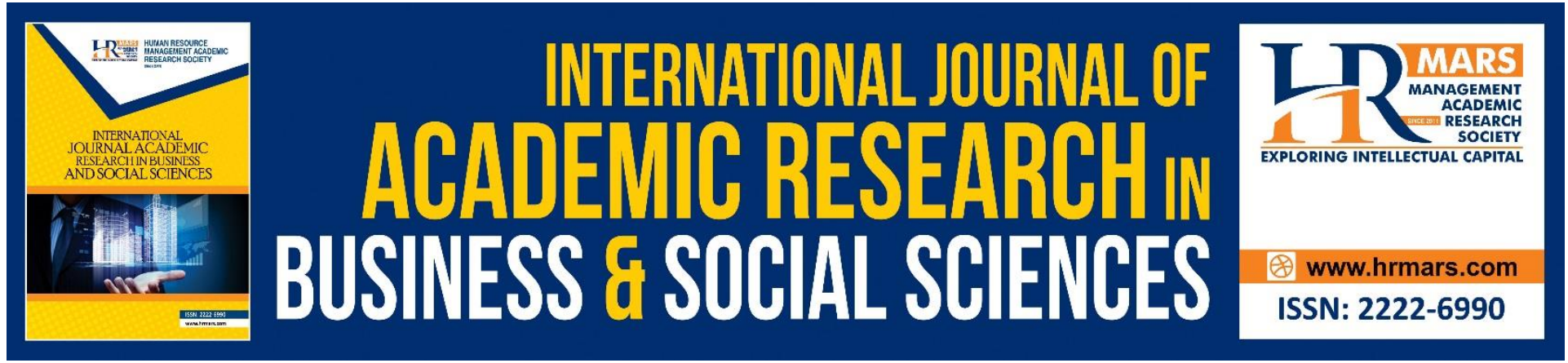

\title{
To Use or Not to Use Monroe's Sequence for Reading? A Preliminary Study
}

\section{Bernadette Peter Lidadun and Nancy Chiuh}

To Link this Article: http://dx.doi.org/10.6007/IJARBSS/v11-i7/10434

DOI:10.6007/IJARBSS/v11-i7/10434

Received: 20 May 2021, Revised: 18 June 2021, Accepted: 30 June 2021

Published Online: 05 July 2021

In-Text Citation: (Lidadun \& Chiuh, 2021)

To Cite this Article: Lidadun, B. P., \& Chiuh, N. (2021). To Use or Not to Use Monroe's Sequence for Reading? A Preliminary Study. International Journal of Academic Research in Business and Social Sciences, 11(7), 183207.

\section{Copyright: (c) 2021 The Author(s)}

Published by Human Resource Management Academic Research Society (www.hrmars.com)

This article is published under the Creative Commons Attribution (CC BY 4.0) license. Anyone may reproduce, distribute, translate and create derivative works of this article (for both commercial and non-commercial purposes), subject to full attribution to the original publication and authors. The full terms of this license may be seen at: http://creativecommons.org/licences/by/4.0/legalcode

Vol. 11, No. 7, 2021, Pg. 183 - 207

Full Terms \& Conditions of access and use can be found at http://hrmars.com/index.php/pages/detail/publication-ethics 


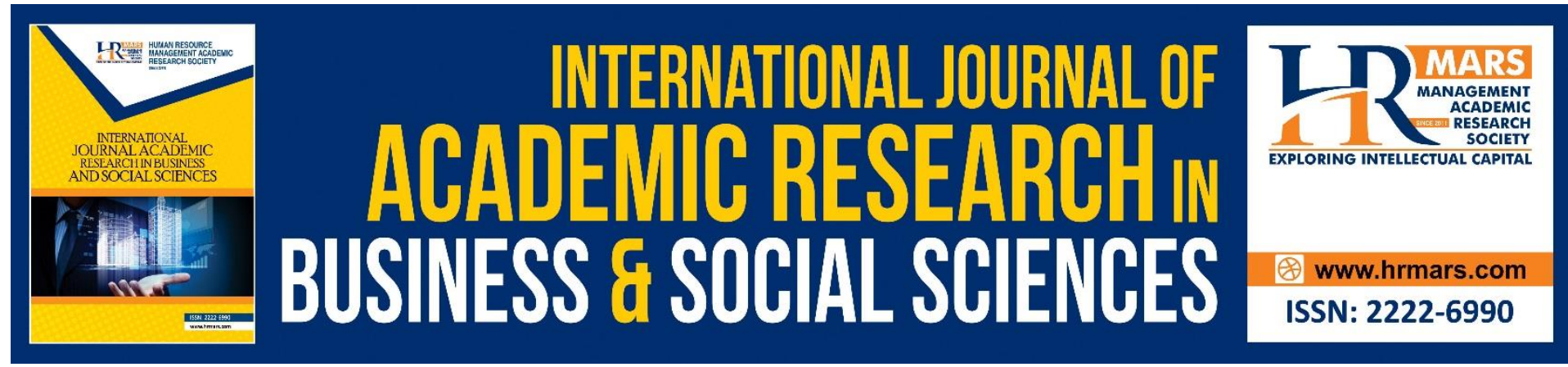

\title{
To Use or Not to Use Monroe's Sequence for Reading? A Preliminary Study
}

\author{
Bernadette Peter Lidadun and Nancy Chiuh \\ Universiti Teknologi MARA, Malaysia \\ Email: bernadette@uitm.edu.my
}

\begin{abstract}
Developed by American psychologist, Alan Monroe, Monroe's Motivated Sequence is believed to be a well-used and time-proven method to organize oral presentations for maximum impact. However, literature indicates that its potential for use in reading development may have been overlooked. This paper reports the findings of a preliminary study which aimed to determine the feasibility of using the 5-step Monroe's Motivated Sequence for reading assignments to a group of aspirants for Catholic priesthood in a Formation House in Malaysia. A phenomenological research was conducted on ten participants between February and June 2019. The objectives of the study were to describe how the 5-step Monroe's Motivated Sequence influences reading behaviors and to explore how it provides the scaffolding for the participants to select their reading materials and the relevant information before they verbally share the information in a class presentation. Through focus group interviews and observations during class presentations, it was concluded that the 5-step Monroe's Motivated Sequence can be used as scaffold for reading activities as it enthused the participants to engage in extensive reading particularly reading materials online. However, the study also suggests that refinement on each step of the Monroe's Motivated Sequence is essential for ESL readers. Some details need to be provided in the steps to form solid scaffolding for the participants to understand better how selection of reading materials and appropriate information can be effectively done prior to oral presentations. This preliminary study managed to ascertain an important aspect that needs fine-tuning before the main study is done.
\end{abstract}

Keywords: Reading Behavior, Scaffolding, ESL Readers

\section{Introduction}

Among the four language skills, reading is possibly the most extensively and intensively studied by experts in the fields of language teaching and language learning. In fact, it could be one of the most demanding tasks for students to gain input for various subjects and fields throughout their learning processes. Reading is on its own a complex process that involves multiple facets which include readers' individuality, reading motivation, reading interest, purposes for reading as well as knowledge of reading skills and awareness of reading strategies (Afflerbach et al., 2008; Beek et al., 2019; Dollinger, 2016; Mokhtari \& Sheorey, 2002). For one apparent reason, the independent relation between reading skills and reading 
strategies creates confusion between the terms and misconceptions about the process of reading may pose as an obstacle to successful reading (Afflerbach et al., 2008). Apart from that, student's individuality, family, and teacher factors play a significant role in children's reading development (Dollinger, 2016; Jensen, 2019, Wu et al., 2019). It is also undeniable that the role of reading is becoming increasingly crucial in this globalized era (Ahmadi et al., 2013; Doležalová, 2017; Jamshidifarsani et al., 2019). Meanwhile, the question on how to motivate students to read is critical and knowing the impact of that motivation on students' reading performance is important in education today (Blyseth, 2015; Lee, 2012; Robinson, 2010). In addition, in order for a student to become a successful and productive adult in society, good reading skills are essential (Netten et al., 2011). Reading performance is usually associated with attitudes toward reading and it seems indisputable that any deficiency to the reading ability can utterly constraint an individual's aspirations in academic achievement and aspirations in life (Baba \& Rostam Affendi, 2020; Karim \& Hasan, 2007; Metsäpelto et al., 2017; Peavy, 2018). This is true as far as education is concerned particularly when the world is now rapidly moving towards utilizing any available technology necessary for quality learning to happen (Sharmin \& Lutfeali, 2017). More research are conducted to determine or create more reading programs and intervention approaches due to the acknowledgement that effective reading is pivotal in this digital era since the advent of technology and the Internet are influencing readers' reading habits and attitude over the years (Cho, 2013; Jamshidifarsani et al., 2019; Karim \& Hasan, 2006). Numerous research in literacy indicate that not only reading behaviors but readers' profiles are also changing due to the impact of digital media and the growth of easily accessible digital information as well as the increasing amount of time people are spending reading online (Baba \& Affendi, 2020; Cho, 2013; Liu, 2005; Putro \& Lee, 2017). In the same vein, Coiro (2011) highlighted that new theories of literacy encompassing both online and offline reading comprehension may be essential to more precisely define and appreciate the complexities of the reading phenomena where readers read via both platforms. Identifying current knowledge gaps and defining future research directions to develop effective reading programs as well as examining the reading skillstrategy relatedness and investigating how an effortful strategy can become an automatic skill for reading are subject to ongoing research and revision (Afflerbach et al., 2008; Jamshidifarsani et al., 2019; Soler, 2017). These research efforts point back to the core of the business in literacy which include to develop or enhance learners' reading skills and strategies as well as to motivate learners to read more and to develop positive reading behavior.

Scaffolds as defined in many ways by numerous studies are appropriately regarded as "tools, strategies and guides to support students in regulating their learning" (Lajoie, 2005 as cited in Beek et al., 2019). With the advent of technology which has led to changes in readers' behavior and preferences (Baba \& Affendi, 2020; Liu \& Huang, 2016; Mizrachi, 2015), learning environments now call for the instructor to not only be successful in determining what it takes for learners who are struggling to become competent readers but also for them to be able to identify some scaffolding techniques that may help the learners in their reading tasks. Many studies have defined and explained what scaffolds are and distinctions in the functions of scaffolds, the modes of delivery and the tools or models by which they are presented are made (Beek et al., 2019; Gibbons, 2015). A study by Salem (2017) investigated whether scaffolding strategies were used by English language teachers for developing their students' reading comprehension skills or simply for assessing their comprehension. It was found that non-native English language teachers were not aware of the nature of scaffolding strategies 
as they were merely using strategies for the purpose of assessing students' comprehension rather than scaffolding their reading. It is recommended that an adequate orientation of the nature of scaffolding strategies, to what extent it should be used (when to begin using these strategies and when to stop using them), be highlighted. The significance of these scaffolding strategies needs to be emphasized for the development of reading behaviors among learners particularly among struggling ESL readers. Providing an effective scaffolding may promote positive attitude towards reading which consequently could lead readers to become skilled in reading. This preliminary study aimed to qualitatively describe how the 5-Step Monroe's Motivated Sequence promotes reading behaviors and to explore how the five steps provide scaffolding for readers to select relevant information from authentic materials. Limitations, practical implications and future research recommendations are given while notable improvement to the model as well as the research procedure on how the reading activity using the model may be conducted in the main study are discussed. The feasibility of using the 5-Step Monroe's Motivated Sequence as a scaffold for reading assignments was then determined.

\section{Literature Review}

Literature indicates that reading culture needs to be inculcated in students particularly among boys. Studies found that there are differences in students' reading attitudes where girls show more positive attitudes towards reading than boys. The large scale research involving a total of 16,622 students across France, Germany, Italy and the Netherlands done by Nonte et al. (2018) has proven this claim. More investigations can be done to determine what should be done and how reading motivation may be instilled in students particularly male readers in general. It is vital that the love for reading whether for academic purposes or for enjoyment is inculcated in students (Blyseth, 2015; Lee, 2012; Netten et al., 2011; Robinson, 2010). While reading skills may not guarantee success for individuals, attainment of success will be more difficult without being skillful in reading. There has also been an emerging major concern which calls for urgent attention regarding reluctance in reading among adults and adolescents who can read but are choosing not to read (Ahmed, 2016; Belzer, 2002; Chien, 2015). Meanwhile, a study by Mulumba (2016) found that even graduates of Language and Literature who were at their Masters level of studies at Makerere University exhibited low reading culture as they did not seem to engage in both intensive and extensive reading which are part and parcel of scholarly and intellectual growth and development. Inability to critically contribute to classroom discussions; failure to analyze issues that emerge in the classroom; failure to critically review pre-tasks such as reading articles and failure to discuss them during the teaching-learning process are some of the problems which stem from lack of reading (Mulumba, 2016). Many may debate that reading is the most important skill for students to be good at due to the complexities of what is meant to have competence in the target language. However, it is undeniable that most fields and scope of jobs require good reading skills and strategies in order for individuals to become more knowledgeable and become articulate and effective in their job performances.

\section{Reading culture in Malaysian Context}

Generally, in Malaysian context, studies were conducted and reports were done with the hope of understanding the factors contributing to proficiency in English and identifying the extent of initiatives that work at improving English language proficiency among Malaysian ESL learners (Heng, 2012; Zainab et al., 2017; Yahaya et al., 2011). Nevertheless, unfavorable 
achievements of ESL learners in their studies particularly their failures in obtaining encouraging results in English examinations may be persistent which usually lead to frustrations to both the learners and the instructors. As reported by Zainab et al. (2017), one of the initiatives taken by four universities in Malaysia was the Malaysia University English Test or MUET Preparation Program (MPP) for graduating students. One university reported that 88 final year students had completed all requirements to graduate except for the fulfilment on getting MUET Bands 2 or 3 (Zainab et al., 2017). Based on another study, language anxiety among Malaysian English language learners in universities who had achieved MUET between Band 1 and 4 prevails and the scenario could be worse when students were aware that English courses in universities were compulsory to pass (Ramiza \& Albion, 2013). The most apparent reason for these continuous problems related to the learning processes and outcomes in ESL contexts is commonly related to the level of proficiency in the English language among the learners. According to the EF English Proficiency (2020), Malaysia is ranked 30 out of 100 countries. The level of English proficiency dropped from 'High' in 2019 to 'Moderate' in 2020 and the ranking lowered by one from rank 29 to 30 respectively. The tenth edition of EF English Proficiency collected data from 2.2 million test takers in 2019 of which test takers were self-selected and a country needs at least 400 test takers in order to be included in the annual statistics. Low performance rates among ESL learners could be associated with the lack of exposures to the language through reading and the lack of force factors for them to use the English language particularly in verbal communication. This phenomenon may also inevitably result in the learners' failure in developing their analytical and critical thinking skills which are both necessary not only in attaining favorable results in any English examination but also in developing these skills and most importantly, in retaining these skills for lifelong use in other subjects and fields. Wilson (2016), in her ethnographic study of three English for Academic Purposes (EAP) teaching-learning contexts in Australia, indicated that students who exhibited a more intense engagement with the content of their reading could develop critical disposition which would be essential for them to do well at university and beyond. Lack of knowledge due to low reading rates and the lack of reading habits proved to be the major obstacles for students in general. Moreover, the habit of reading in Malaysia was found to have deteriorated with the prevalence of digital devices. For example, a research by Annamalai and Muniandy (2013) found that polytechnic students in Malaysia had low interest in reading and that students were found to enjoy other technology related activities rather than reading. In another research involving a group of 314 Malaysian undergraduate students, despite having positive attitudes toward reading, it was found that the students seriously lacked proper reading habit and practice both intensively and extensively (Ahmed, 2016). Perhaps, fun and light activities that incorporate reading as well as introducing mind mapping and speed reading to students could make reading more fun in English classrooms which consequently may develop reading habits that will shape lasting reading behaviors in students. Many may suggest that English language instructors can include monthly book reviews and oral presentations as assignments to instil good reading habits and inculcate critical thinking in learners. Although giving oral presentations as assignments may work for students, the monthly book reviews might not. This is due to the fact that students including those who have positive attitude towards reading would prefer to engage in other things rather than reading (Ahmed, 2016; Annamalai \& Muniandy, 2013). 


\section{Reading Skills vs Reading Strategies}

The three phases of a reading activity are commonly known as the pre-reading, while-reading and post-reading phases by educators and language practitioners in general. Each of these phases plays its own role and is essential for effective reading to occur in order to achieve the desired outcomes - enhancing students' reading skills and strategies as well as developing reading behaviors which consequently result in reading achievement. Nevertheless, according to Afflerbach et al. (2008) there is inconsistency in the use of the terms 'skills' and 'strategies' which confuse students and teachers alike and thus, the teaching and learning processes in reading may become less effective. Although tedious to do, explicit instructions on both skills and strategies must be emphasized. It is recommended that explanations are given to students on how to think and there is a need to "model, describe, explain and scaffold appropriate reading strategies" (Afflerbach et al., 2008: p.370). In order to develop reading skills, a reading instructor is often expected to be able to observe certain characteristics exhibited by learners as it is believed that unmotivated and struggling readers may not be persistent in their quest to increase literacy and thus, they need prompting and support. In addition, distinctions between cognitive and metacognitive strategies must also be understood by the instructor to be successful in providing support to learners throughout the reading process. Other supports for reading development include motivational and affective aspects. Since reading development exudes complexities and various aspects need great considerations, scaffolding for reading may need to be developed to help students especially struggling readers to develop not only skills and strategies but to develop positive attitude and reading behavior.

\section{Scaffolding Adult Reading with Reading Instructions}

Lev Vygotsky's Zone of Proximal Development (1978) was used as the initial reference on the theory of scaffolding for this preliminary study even though the prospects of referring to other new insights and models related to reading development like the self-regulated learning (SRL) by Zimmerman (2008) and the multi text comprehension by List and Alexander (2017) would be kept in view for discussions. In any research, this is essential in order to keep abreast with the current trends in general learning and particularly in language learning for example, the advent of technology which has been found to have altered the reading behavior among readers. Vygotsky's ZPD highlights that in order to help learners achieve independent learning, they should collaborate with an experienced instructor or more knowledgeable peers to complete small, manageable tasks which leads to making connections between concepts (Kurt, 2020). Investigating how scaffolding may be used in developing reading behaviors of a specific group of adults may not be similar to investigating reading behaviors of children and adolescents. However, theories of scaffolding and reading instructions remain the crux of this study. Since this preliminary study investigated reading behaviors of male adults, it was necessary to also refer to the theory for adult learning by Knowles et al. (1998) which outlined the core adult learning principles, individual situational differences and the goals and purposes for adult learning. According to Knowles et al. (1998), adult learners have the need to know about why they need to learn something, what they need to know and how they will learn things. Adult learners are also autonomous and have a deep need to be selfdirecting. Previous experience and readiness to learn with intrinsic motivation are also among the principles of andragogy. Most importantly, the orientation to learning that is contextual and problem centered for adult learners could be a match for reading tasks which incorporate researching of relevant information and providing solutions to problems and issues as 
required in the 5-Step Monroe's Motivated Sequence. As stated by Afflerbach et al. (2008), successful reading is a balance between application of reading skills and employment of reading strategies accompanied by the ability of the reader to shift between the two. This shifting balance will be determined by the difficulty of the reading which is influenced by text, task, the reader, and contextual variables. This is supported by the investigation by Latini et al. (2019) where they found that there were interaction effects of reading medium (printed versus digital texts) with reading purpose on behavioral engagement indicators of reading time and the length of the post-reading written products by the learners. Meanwhile, Kung (2019) reported that learners preferred metacognitive to cognitive strategies when it comes to reading English texts while authentic reading materials were found to positively increase learning motivation as well as attitude due to several reasons.

Generalizations on findings in numerous research for literacy include the beliefs that individual characteristics of readers shape their reading behaviors which comprise their abilities to understand important information in reading passages; to self-correct and reread information when necessary to enhance understanding; to use some reflective thoughts; to read merely for enjoyment or to discover something; and to demonstrate a positive attitude toward reading. Apart from that, making effective use of cueing systems, bridging in background information and moving from merely having the ability to recognize words to being proficient in reading for meaning are the expected characteristics of a proficient reader. The shifting balance in reading processes as mentioned by Afflerbach et al (2008), the theory for adult learning by Knowles et al (1998), and the collective ideas about the complexities of reading by researchers in reading are fundamental to determining the feasibility of using the 5-Step Monroe's Motivated Sequence. In order for ESL adult learners to successfully accomplish a reading task, scaffolding reading instructions may still have to be provided for them as support to fulfil the adult learning principles. This is most likely true for ESL adult learners whose proficiency in the English language falls between A2 and B1 (Basic and Independent User) according to the Common European Framework of Reference (CEFR).

In their attempt to evaluate the effectiveness of reading programs at improving the reading skills and academic achievement of 4108 primary school students in rural China, Qiufeng et al. (2018) found that students exhibited low levels of reading achievement, independent reading quantity, and reading confidence in the absence of any treatment. Nevertheless, results of their findings also suggest that properly designed treatments may improve the reading and academic outcomes of students. An increased access to independent reading materials with effective teacher training resulted in substantial improvements in not only reading skills but also in math test scores and Chinese test scores of the students. Quifeng et al. (2018) believed that these improvements are due to changes in reading instruction and the attitudes of teachers toward reading. These findings indicate that encouraging higher reading quantity and providing high-quality reading instruction are imperative to improve students' achievement in developing country settings. It is therefore pivotal that reading instructors provide carefully planned reading instructions to ensure that effective and successful reading could happen (Morefield, 2013). Generally, effective scaffolding and modelling by teachers and instructors are believed to have a profound influence on how much students learn (Rupley et al., 2009). Similar to what was explained by Afflerbach (2008), Rupley et al. (2009) believed there is a possibility that struggling readers could learn important reading skills and strategies if direct and explicit model of instructions were used by the 
teachers and instructors. Meanwhile, in his thesis, Matterson (2015) discussed that understanding fully the nature and process of student learning, engaging directly and regularly with the learning process, exhibiting evidence-informed leadership and modelling deep adult learning perspectives coupled with reflective teaching practices by teachers were the key principles of effective literacy instructions. A quasi-experimental study done by Zhang (2007) on Chinese ESL adult students who were preparing for further education in an Englishmedium university in Singapore discovered that the ESL students' use of reading strategies was influenced by the teacher's strategy-based instructional intervention which resulted in the students' improvement in comprehension. Literature vastly indicates that scaffolding reading development is still currently relevant despite the changes in reading behaviors among readers due to the explosions of accessible information in digital texts. In fact, high accessibility to authentic materials and reading texts via many platforms may even pose more challenges to ESL readers and thus, more scaffolding strategies will be needed in reading development which begins as early as in kindergarten (Dobzyniak, 2020). This is also supported by a study conducted by Brevik (2019) where 60 video recorded ESL lessons in lower secondary schools in Norway were analyzed to investigate how reading comprehension is instructed, scaffolded and framed in actual secondary school settings.

\section{The-5 Step Monroe's Motivated Sequence}

This preliminary study aimed to describe how the adaptation of the 5-Step Monroe's Motivated Sequence may provide the scaffolding for ESL learners to develop their reading behaviors. Developed in the mid-1930s by American psychologist, Alan Monroe at Purdue University, Monroe's Motivated Sequence has since been well-used and has been claimed to be a time-proven method to organize presentations for maximum impact not only in education but also in the corporate and political world. It can be used for a variety of situations to create and arrange various components of any message or topic of presentation. This model is widely used by communication teachers in schools and in public speaking courses in colleges around the globe for examples, Haugen and Lucas (2019); McDermott (2004); Parvis (2020) and even in textbooks for public speaking courses like Lucas (2015). Nevertheless, academic investigations on the usefulness of this model are very scarce and its potential to create impactful learning especially on reading has not been explored. In this preliminary study, instead of merely using this model for a public speaking module, the 5-Step Monroe's Motivated Sequence was adapted to be used as a scaffold to develop reading behaviors in ESL students. This preliminary study aimed to describe how the research participants experienced their reading processes and how they dealt with each of the 5 steps to fulfil the required tasks which included answering questions and synthesizing information pertinent to the issue within the scope of the reading task assigned. In other words, this study aimed to describe the research participants' experiences on how they searched for reading materials, identified and selected the most relevant information to fit into each step of the model to accomplish the reading task based on assigned topics before they did a verbal presentation. It was anticipated that the verbal presentations would be the catalyst in creating the avenue for the research participants to be more responsible and accountable for their reading. In other words, the verbal presentation served as a platform for sharing the knowledge they acquired throughout the reading processes where the research participants were expected to exhibit observable and notable actions that would reflect the participants' reading experiences whether they were able to decipher information from their reading and organize a coherent presentation by using the adapted 5-Step Monroe's Motivated Sequence. 
It was presumed that positive reading behaviors among the research participants would be observed in the study because the participants felt that there was a purpose for them to engage and immerse themselves in reading. Though this preliminary study focused on how the features of this model may be able to develop reading behaviors, there was also a presumption that the reading tasks simultaneously led to the development of communication skills as well as analytical and critical thinking skills and vocabulary building among the research participants

\section{Method}

\section{Participant}

This preliminary study involved the entire population of the Year 2 aspirants (aged between 19 to 36) who enrolled as aspirants to Catholic priesthood in January 2018 at the Formation House, Catholic Archdiocese Centre Kota Kinabalu, Malaysia. All aspired to be enrolled as seminarians to study psychology, philosophy and theology in order to be ordained as Diocesan priests serving the Catholic church. Despite the differences in age and past experiences as well as coming from various districts of the state, they shared the same experience being aspirants in adapting to the community life, to receive spiritual directing and to study the basics of sociology. They also had similar exposures to and background of ESL learning contexts in the Malaysian school settings. Aspirants are given two years at the Formation House to adapt to the community life, and most significantly, to study English to attain a compulsory Band 4 in MUET at the end of their second year. It has to be noted that students who will embark on tertiary education at institutions where the medium of instruction is English will experience a certain level of anxiety. Nevertheless, it was anticipated that although the aspirants may be motivated adults learners based on Knowles' (1998) adult learning theory, this anxiety should be manageable for them. The priest in-charge of the aspirants was also identified to be an important key participant in this preliminary study. The priest (34 years old) was identified as a participant because of two reasons: firstly, he was the Rector for the Aspirant Formation House when the aspirants enrolled at the Formation House in 2018; and secondly, he was an independent observer during the research participants' preparation and presentations for the reading assignment and oral presentation project meant for the purpose of the preliminary study. Written consent was given by the organization to conduct the study and informed consent was given by all participants prior to data collection. It was not mandatory to submit research ethics approval to the local institutional research ethics review committee when the preliminary study was conducted.

\section{Procedure}

Classroom activities were planned for a span of fourteen weeks between February and June 2019 (see Figure 1). The classroom activities began with some ice-breaking and interactions before the researcher-instructor made the announcement that the research participants would be doing class presentations. The first set of 10 topics for informative speech (Task 1 ) were assigned to the 10 aspirants. Each research participant was individually assigned a topic. The rationale for doing the informative speech was to let them be ready for the more difficult task of doing a persuasive speech employing the 5-Step Monroe's Motivated Sequence. All research participants were given the freedom to choose their own reading materials ( 3 different articles of the same assigned topic) to prepare their presentation. They were also informed that the maximum number of slides was 3 and the length of presentation was between 4 to 6 minutes. Upon completion of the first set of informative speech presentations, 
another 10 informative speech topics (Task 2) were assigned. However, the nature of topics for Task 2 was one that was more intense and controversial, for examples, abortions and LGBT. Instructions given for Task 1 and Task 2 were the same. Task 1 and 2 were done and completed by the end of March 2019. Next, the dynamics of the 5-Step Monroe's Motivated Sequence were introduced and explained using YouTube videos and a lecture handout on the model. The research participants were also encouraged to search for further information regarding the model via the Internet. Topics for persuasive speech were assigned individually (Task 3). The research participants were given 2 weeks to prepare and the autonomy to choose 5 reading materials from any platform. The research participants were informed that the length of time for the presentation was between 8 to 10 minutes and the maximum number of slides for the presentation was 8 . Once Task 3 was completed, class discussions were done and feedbacks were given. Five of the research participants who were scheduled to do the presentations in the evening were informed that the priest in-charge would be listening to their presentations. Task 4 which had another 10 persuasive speech topics was assigned at the end of April 2019. However, the topics accompanied with speech outlines (consent for use by local university student writers and checked for language accuracy by the researcher) were given together with 5 accompanying reading materials based on the topic assigned. The research participants were encouraged to look for additional reading materials which they felt necessary. The length of presentation was also between 8 to 10 minutes. Meanwhile, the maximum number of slides was 10 . All presentations for the Task 4 concluded by the second week of May 2019.

\section{Instruments}

2 lists of topics for informative speech (Task $1-10$ topics) and (Task $2-10$ topics)

1 list of topics for persuasive speech (Task $3-10$ topics)

1 list of topics with prepared speech outlines and prescribed 5 reading materials

Lecture handout on the 5-Step Monroe's Motivated Sequence (5-S MMS)

Semi structured interview questions based on Survey of Reading Strategies (SORS) (Mokhtari and Sheorey, 2002)

Semi-structured informal interview questions which aimed to collect perceptions of the priest in-charge was developed by the researcher and forwarded prior to the interview session with the priest by the researcher. 

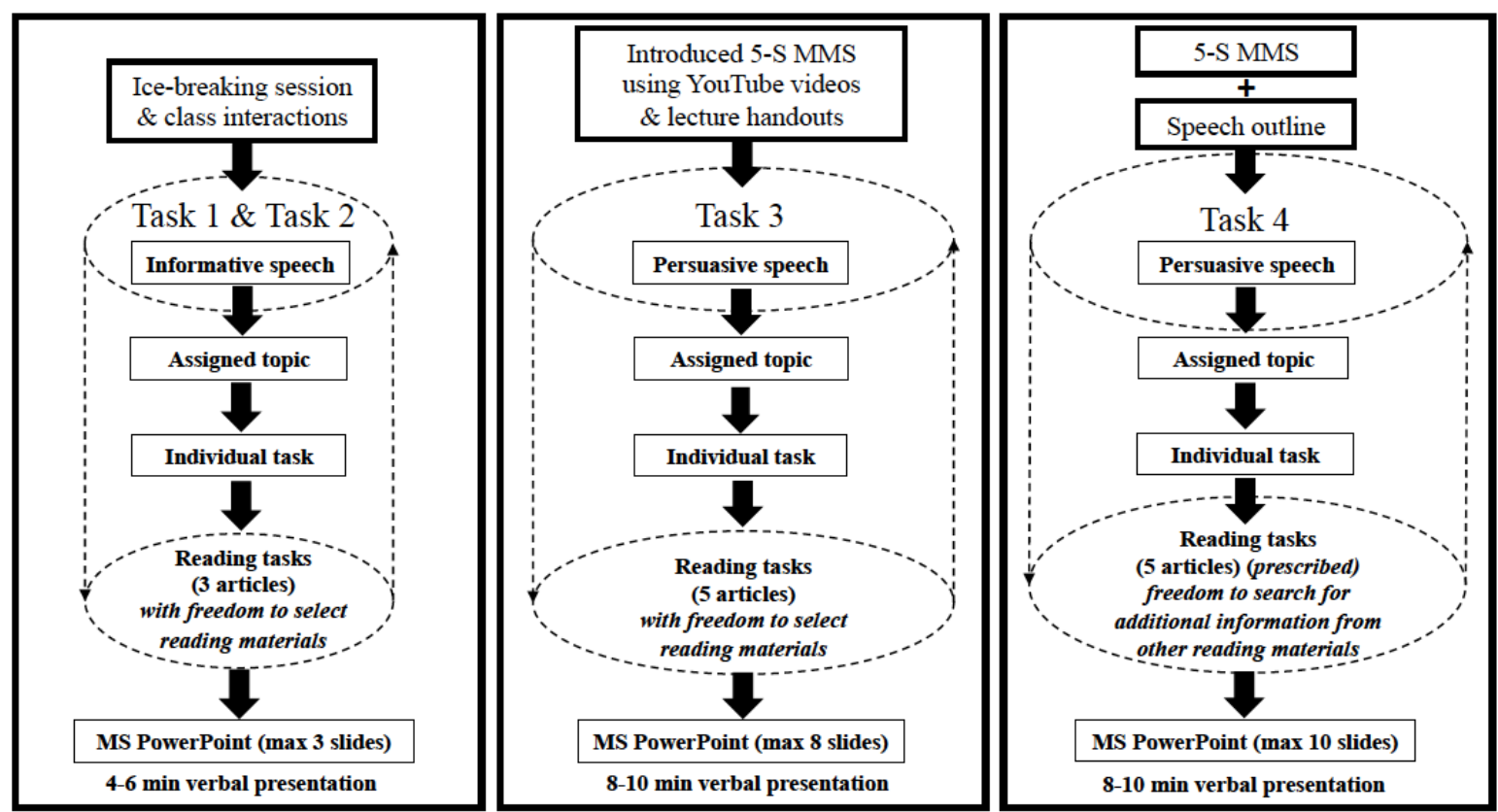

Figure 1. Classroom activities for aspirants at Formation House, CAC KK, Malaysia (February - June 2019)

\section{Data Collection}

Data collection via observations were done within the 14 weeks. Interactions during class presentations between the researcher and research participants as well as research participants with their peers were also noted when necessary. One session of focus group interview which lasted for 2 hours and 15 minutes was done on the 17 May 2019 in the afternoon, four days after concluding all the given tasks for the classroom activities with involving all the 10 research participants. Some photos as well as occasional short video recordings were taken during the class presentations particularly to capture the visual aids used by the research participants and to note how they shared their newly-gained knowledge and how they gathered their reading materials, where and what reading materials they gathered. An individual interview which lasted 40 minutes with the priest who was in-charge of the research participants during the investigation was also done on 17 May 2019 in a separate session in the morning. The interview with the priest aimed to collect data on his perceptions on the level of proficiency in the English language as well as the general attitudes of the research participants towards English and his daily observations on the research participants while they were doing the reading tasks. His input regarding the outcome of the reading activity and the verbal presentations done by the research participants were collected to supplement the researcher's own observations. The process of data collection began as soon as the commencement of the class activities. The details of data collection are summarized and shown in Figure 2.

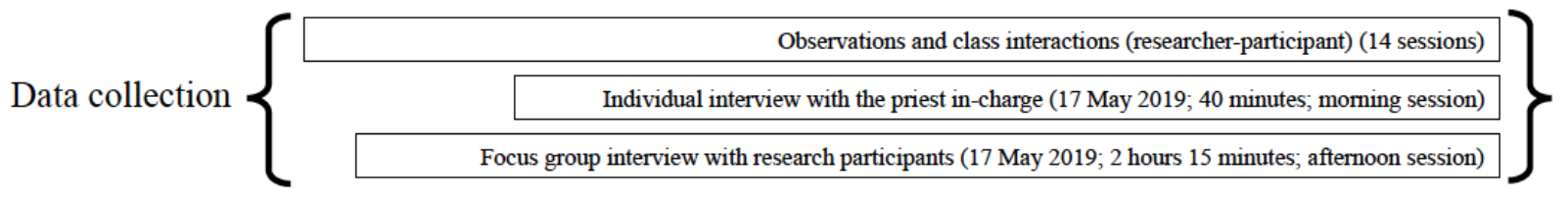

Figure 2. Data Collection 


\section{Methodology}

This preliminary study employed the phenomenological research methodology as described by Creswell \& Poth (2018); Moustakas (1994). Descriptive qualitative research design was adopted due to appropriateness of the nature of the study where for one apparent reason, the sampling size was inevitably small although it was the whole population. A phenomenological study examines the commonality of lived experiences of a particular group of research participants which were described accordingly within the specific context of the study within a time frame deemed sufficient for the investigation. Employing the abductive research approach, this study moved from relevant collected data to the mapping of theories and presumptions. Though some theories (Vygotsky's ZPD; Knowles, 1998) Andragogy Theory) and theories on literacy were discussed as reference for the research plan, the research plan was designed in a way that it moved from the collected data which were then mapped with the theories where relevant. Therefore, the main goal of the abductive approach in the proposed actual study would be to arrive at a description of the nature of the particular phenomenon based on the data collected from the field of investigation guided by some initially selected theories sufficient enough for the investigation to get some answers to the research questions of the investigation. Nevertheless, it must be clarified at the initial stage of the research proposal of the actual study that though the abductive approach is employed, the investigation does not aim to formulate any new theories. The approach simply aims at describing the possibility that a model - the 5-Step Monroe's Motivated Sequence is able to serve to some extent its purpose as a scaffold in the development of reading behavior among ESL readers.

\section{Data Analysis}

This preliminary study was a phenomenological study. Therefore, the distinction between two main approaches to phenomenology: descriptive phenomenology by Edmund Husserl and interpretive phenomenology by his student, Martin Heidegger was determined based on Sloan and Bowe (2014) in order to justify how data analysis was done. The researcher employed the descriptive phenomenology as its method of analysis. Hence, data analysis involved six stages which were influenced by the work of Husserl as outlined by Moustakas (1994). The process of data analysis is illustrated in Table 1.

Collected data via voice-recording during the focus group interview with the aspirants and the individual interview with the priest in-charge were transcribed. Reorganization and bracketing was then done where occasionally the researcher had to refer to her own personal experiences in learning the English language particularly in reading as a college and university student. This was done to fully understand the aspirants' observed behaviors and descriptions of their experiences throughout the 14 weeks of classroom activities. Horizonalization was done next where significant statements given by the aspirants in describing their experiences were highlighted and noted before the clustering of meanings was done. The thematic coding was done where the statements given by the aspirants were categorized into identified emerging themes. Then, textural description which highlighted what experiences the aspirants had during the class assignments was done. The context and setting that influenced how the aspirants experienced the whole classroom activities within the 14 weeks was then described. Finally, the presentation of data was written in a narrative form. The whole process of data analysis led to the textural and structural descriptions which present the essence of the phenomena. Findings and discussion are then presented as clearly as possible. 
Table 1. Data analysis

\begin{tabular}{ll}
\hline & Descriptions \\
\hline Step 1 & Reorganization and bracketing of collected data \\
Step 2 & Horizonalization (identifying significant statements about experiences) \\
Step 3 & Clustering of meanings into different themes (thematic coding) \\
Step 4 & Textural description (what are the experiences of the participants?) \\
Step 5 & $\begin{array}{l}\text { Structural description } \\
\text { (the context and setting that influenced how participants experienced the whole } \\
\text { process) }\end{array}$ \\
Step 6 & $\begin{array}{l}\text { Presentation of data in narrative and/or graphic forms } \\
\text { (Textural and Structural = The Essence of Phenomena) }\end{array}$
\end{tabular}

\section{Findings and Discussion}

Overall, the learning activities that incorporate reading assignments which required the research participants to verbally share the new information they had read as illustrated in Figure 1 could be planned to deal with the observed scenario of the general use of the English language at the Formation House. Such classroom activities may somehow be difficult and stressful for the aspirants to accomplish considering that most of them lack the proficiency. Based on Vygotsky's theory (1978), learners should be able to reach certain learning objectives by participating in the learning activity. The preliminary study apparently found that the given tasks were stressful to a certain extent to the participants due to several factors. The priest in-charge reported that the participants burnt the midnight oil for many nights in preparing for their presentations. Some external factors which contributed to their stress included limited availability of computers and controlled Internet connectivity. However, it was also observed that the participants wanted to do their best in preparing their speeches not only because it was their first time having such purposeful reading assignments but also due to the fact that it was going to be their first time doing such presentation in front of an audience. According to the priest in-charge, the aspirants took the reading tasks and the preparation for the presentation seriously although they were feeling a certain level of anxiety.

The research participants all agreed that time constraint in preparing the presentation as well as the time limit to present also contributed to their stress. This was due to the fact that as aspirants to the Catholic priesthood, the research participants were living as a small community with a schedule which required them to do various daily activities at the Formation House. They described that they were only able to spend about an hour at night before bed time to search for the reading materials, to select relevant information from the materials, and to prepare their presentation. The participants reported that the nature of the tasks and the fact that they had limited resources at the Formation House were overwhelming. In addition, limiting the presentation time contributed to a certain level of stress for the participants. During the presentation, some of them displayed panic behaviors and confusions that led them to be uncertain of which information to present first or which information were more important to present even though they had prepared the slides as instructed. It was observed that this was mainly due to their inability to digest the information and to summarize and synthesize the information enough for them to remember their overall flow of presentation and partly due to time constraint and lack of facilities in preparing the visual aids. Many of the slides were cluttered with words. It was consistently observed that 
those who were presenting with cluttered visual aids were less able to explain the topic or the issue they were presenting for all the 4 tasks. There would be a need that prior to assigning the reading tasks for their oral presentations, reading skills (summarizing and paraphrasing) be taught to ESL students as a separate set of skills. Apart from that, it may be necessary to conduct a session on how to develop effective visual aids for presentations. Setting the time limit as a normal practice for speech presentations was nevertheless considered very essential by the priest in-charge and should therefore be done even though some of the research participants said that they would have preferred longer time for the presentations. Learning to adhere to time limit was crucial for the research participants due to one main reason where a priest needs to be able to do homilies which are impactful within a short span of time during masses and other religious events. A large scale study done by Pew Research Centre in 2019 found that the Catholic homily is the shortest with an average of 14 minutes with 1,847 word count. The study collected 49,719 sermons delivered via online between April 7 and June 1 in 2019 from websites of 6,431 churches (Pew Research Center, 2019). Since the 5-Step Monroe's Motivated Sequence has been a model appraised for its effectiveness in persuasive speech presentations, it could prove to be one strategy which aspirants at the Formation House need to learn and be familiar with during their formation years. Apart from that, it was suggested by the priest in-charge and the research participants themselves that the duration of time to prepare for the classroom activity should be ample for them to allow them to deeply search for and carefully select reading materials and reorganize relevant information to fit into the 5-Step Monroe's Motivated Sequence for a smooth flow of presentation. This calls for a more thorough and careful planning of the classroom activities with consideration of many aspects in the Formation House by the researcher-instructor.

The research participants were constantly reminded that their presentation had a time limit and a maximum number of MS PowerPoint slide was emphasized. Therefore, the skills in skimming, scanning, identification of main ideas, selecting only relevant and interesting information, paraphrasing and summarizing the useful information wherever and whenever necessary as well as strategies in planning the presentation by organizing the information they had gathered through reading had to happen incidentally for all the five steps. These integrated skills and strategies appeared to be pivotal in helping the research participants not only gain new knowledge and expand their minds, but the reading processes opened an avenue for them to acquire some useful new vocabularies incidentally. The fact that they were reading in English to discover new knowledge consequently promoted incidental learning and acquisition of the English language to a certain extent. As discovering new things is exciting, researching for information related to the given topics should be exciting for the participants. Nevertheless, it should be incorporated in the reading assignment that the research participants read at least one book which is related to the assigned topic rather than giving them the freedom to choose online material as their sole platform for reading. This is important to note as Pfost et al. (2013) in their longitudinal study involving 1226 secondary school students, confirmed the importance of traditional book reading for the development of reading comprehension and vocabulary. They also critically discussed reasons why reading traditional print media for student's literacy development cannot be compensated fully by online reading activities. This sheds some light that the choice of topics for this class activity must be given careful consideration in various aspects. Topics that are given must be those which should be new knowledge, interesting and challenging the minds of the aspirants. The choices of topics assigned during the preliminary study were found to be quite encouraging 
and enjoyable by most of the participants. However, more topics which are relevant to the field of studies for the participants can be introduced based on advice by the priest in-charge for the actual proposed study. When the research participants were asked about their opinion on Task 4 (where the speech outline was given and the materials were prescribed), all of them did not like the idea of using the speech outlines prepared by other students. They explained that 'looking' at the materials gathered by other students was boring and unexciting. They described that it required them to memorize the speech rather than to talk about their own ideas of the topics assigned based on what they gathered through their own reading. In other words, they preferred to search for their own reading materials. This indicated that the assignment of topics accompanied by a thorough explanation about the 5-Step Monroe's Motivated Sequence and a modelling of an example speech outline would be sufficient.

The preliminary study found that all 10 participants utilized only the Internet to search for their reading materials. When asked whether they used other sources of information, all participants exclaimed that using the Internet was the easiest thing to do as they could simply type the topic and search for reading materials until they thought they had found something relevant and interesting to use and share. This finding relates to the findings of the study by Karim and Hasan (2007) that web sites have become an increasingly popular hub among Malaysian students for their reading resources. It is becoming apparent that the pattern of reading may never be the same as reading as it was known in the past (Cho, 2013; Jamshidifarsani et al., 2019; Karim \& Hasan, 2007). The Internet does provide a wealth of information, however, at least three of the participants mentioned that they were overwhelmed by the overload of information offered by the Internet that it was difficult for them to choose and identify the most relevant information. One participant said that he needed guidance and 'a lot of help' in selecting the right kind of reading material as he said he was confused with his reading. Referring to the theory of purposeful reading by Rouet et al. (2017), this participant must be a typical example of what Hautala et al (2019) described as a reader who "implicitly or partly consciously construct a context model, a task model, and a text model". This calls for the researcher-instructor to provide further and explicit guidance and scaffolding to make sure that learning and reading can still occur particularly in the context of this preliminary study. Perhaps, it has become a norm among students in general to search for reading materials via the Internet hence, reading habits of students are inevitably changing due to the advancement of technology. Whether it would be effective or not, students themselves would need to experience reading materials both in print and on screen. And, though reading skills and strategies may still be the same from decades ago to the present, due to the advancement of technology, reading may pose to be a challenge to most students. This phenomenon requires further investigation on what skills and strategies students have or may not have that will inevitably either foster their overall learning or impede their capacity in learning new knowledge through extensive reading in English via the Internet. As mentioned by Coiro (2011), even new theories of literacy may need to be developed.

The 5-Step Monroe's Motivated Sequence was used in the preliminary study as a scaffold for the research participants to be able to carefully select reading materials and properly plan their presentation. They were supposed to come up with relevant $\mathrm{WH}-\mathrm{Q}$ s while preparing for the presentations. This should allow them to practice analytical and critical thinking skills. However, it was observed that although the participants did select reading materials related 
to their topics, a lot of information that they shared during the verbal presentations were seen as 'useless' and should not have been there. The priest in-charge believed that this calls for the instructor to play an important role in guiding the participants in skimming, scanning and identifying main ideas in the reading passages. The ability to identify the main ideas and the central issue in the reading passages can ensure that the information selected and shared by the participants in their presentations are relevant and consequently, the presentation should be coherent. In other words, the participants were not quite able to have a good grasp of the model in developing a persuasive speech of policy without being given clarifications of what they needed to do for each step. It was observed that their speech presentations after their reading assignments were merely informative rather than persuasive. Therefore, it was noted that in the actual proposed study, the relevant WH-Qs should be modelled clearly with examples in the lecture handout by the instructor instead of putting the responsibility on the research participants. This would add a more solid scaffolding to the model used.

Although the research participants may have presented information that were seen irrelevant as emphasized by the priest in-charge, being able to present something in English in front of an audience had somehow exhibited their confidence in using English more. Besides that, the research participants claimed that they had fun during the presentations despite the stressful nights of preparation. It may be concluded that learning activities which require the participants to read purposefully and to use English in sharing verbally what they had read may seem to be able to help them pick up the language to a certain extent and accordingly, they would attain a certain level of proficiency. Therefore, it is possible to note that one of the most important keys to improving language proficiency among ESL learners is to have them read more. Reading activities at the Formation House seem to be heavily focused on reading their prescribed textbooks which are MUET textbooks although there were other reading materials like magazines and Reader's Digest available for reading. As proposed by Guthrie and Wigfield (2000, p.405) that "reading motivation is the individual's personal objectives, values, and beliefs regarding the topics, processes, and outcomes of reading", the classroom activities where the 5-Step Monroe's Motivated Sequence was introduced to the participants may prove to be beneficial to the participants in giving them the purpose to read and gain knowledge of the world. A wide range of reading materials should be made accessible for the students in order to develop the love and desire for reading. Knowledge gained through reading can be shared in speech presentations. Apart from that, the research participants mentioned that assignment of carefully selected topics should be done by the instructor rather than for them to choose their own topics. Two participants explained that if the topics were for them to choose on their own, they would have selected topics that may be familiar to them and therefore, it would not be challenging for them. For example, one participant said that he was glad that he was given the topic on 'China's One-Child Policy' for at first he thought it was difficult but after searching for reading materials about it, he gained a lot from the reading. Hence, being assigned topics which were unfamiliar for both the informative and persuasive speech had been a good challenge and the learning became meaningful as they gained new knowledge. The research participants exhibited excitement on the day when the topics were assigned. This phenomenon created an avenue for the research participants to co-create their learning activities with the instructor which according to Gros and Lopez (2016) is one of the critical factors essential to generate the trust between learners and instructors particularly in technology-rich learning activities in higher education. The preliminary study also found that more time would be needed for quality learning 
environment to occur. It is perceived that target students would not only need input on what reading skills and strategies are but they would also need guidance and coaching for oral presentation techniques by the instructor if the 5-Step Monroe's Motivated Sequence was to be incorporated in the learning activities. These were all noted by the researcher in order to improve the research plan and to identify further possible investigations which could stem from the investigation on the feasibility of adapting this model as a scaffold for reading development.

In order to make the classroom activities helpful, however, it must be acknowledged that the classroom has diverse personalities with different levels of proficiency in the English language. More attention and appropriate approach are definitely going to be essentially given to those who lack the proficiency. According to Vela (2015), teachers may use reading comprehension as an aid for intentional and incidental vocabulary growth. However, the fact that many reading passages contain low frequency words can cause difficulties for learners to comprehend L2 texts (Vela, 2015). This can become an obstacle in the process of vocabulary learning. Thus, Vela (2015) suggested that including glosses in reading texts is an effective strategy that helps students overcome this problem. Vela's (2015) study indicated that in both levels the experimental groups outperformed the control groups. Low proficiency students especially benefited from the L1 glosses and high proficiency students were successful with both gloss conditions. It would be crucial for the researcher-instructor to be ready in giving more attention and guidance to the research participants. However, what kind of guidance and to what extent the guidance should be given must also be considered. Perhaps, the proposed research plan would then need to include an additional session during the oral presentations where the participants would need to share new vocabulary they have learned and explain the words as used in the reading contexts. On a different note, a study by Niazifar and Shakibaei (2019) seems to disagree with what Vela (2015) claimed. In contrast to the common perception that easy materials may increase the reading motivation of EFL learners, the findings of the study done by Niazifar and Shakibaei (2019) proved that the more difficult materials increased Iranian EFL learners' motivation towards reading English texts. Though there might be differences in ESL and EFL learning contexts, it seems fair to say that this learning scenario may be similar to ESL learning contexts where the learners are under A2 and B1 of the CEFR level of proficiency. Therefore, reading materials with higher level of difficulty may have some discovery natures to these groups of ESL learners. This means students would want to discover and understand new things. Meanwhile, Chiang (2015) who investigated the different text difficulty levels on $L 2$ reading perceptions and reading comprehension found that diverse difficulty levels of reading text did not significantly influence participants' reading. Hence, finding the most feasible and beneficial approach for the research participants to best learn and upgrade their proficiency in the English language through reading needs conscientious planning and consideration of many aspects.

It has been reported that many students have difficulties understanding discipline-specific content of written texts and therefore disengage themselves from reading (Van Rijk et al., 2017). In general, students' motivation to read decreases in the higher grades of primary school and in secondary education. It is also believed that taking additional measures is essential to prevent functional illiteracy and detachment in primary school (Van Rijk et. al., 2017). Preventive measures should be taken at the initial stage of the problem rather than to try to address it in secondary school. Inspired by Vygotsky's Zone of Proximal Development 
(ZPD) theory, many researchers have investigated what effective and motivating learning environments and educational strategies are needed to teach reading for comprehension to all students. Due to the fact that certain texts can be difficult to understand, language instructors should supply the tools needed for understanding, such as reading strategies, and scaffold the reading of these texts while posing questions for the learners which eventually makes the texts personally interesting and relevant for them. In other words, with Vygotsky's ZPD, learners should be able to maximise comprehension with the provision of suitable scaffolding by the teacher for any given reading activities. Meanwhile, Hamidi and Bagherzadeh (2018) stated that many scholars in the field of second language acquisition (SLA) suggest that scaffolding promotes learning or fosters second language (L2) development. On the other hand, in-depth research on the effect of scaffolding on L2 development in SLA has no strong empirical evidence to determine whether, and to what extent, it enhances interactional processes among the target language learners, builds up learners' target language proficiency, contributes to learners' greater noticing to the target language features, boosts learners' self-confidence, autonomy, and motivation, and displays more social roles in their classroom learning. Moreover, according to Hamidi and Bagherzadeh (2018) there are also no empirical studies which have confirmed the impact of scaffolding on L2 learners' interlanguage development. Nevertheless, in their longitudinal study, Muijselaar et al. (2017) found that there was a unique effect of reading strategies on reading comprehension, and also of reading comprehension on reading strategies. One major problem in studies on the relations between reading strategies and reading comprehension is how the knowledge and use of reading strategies are measured. This calls for more rigorous studies which employ tested instruments in measuring reading strategy awareness like the Survey of Reading Strategy (SORS) by Mokhtari and Sheorey (2002) which was developed specifically for ESL learners.

An initial stage of the proposed actual investigation would be to determine the attitudes of the research participants towards reading English texts in general. The second stage of the investigation should also determine what reading strategies are used by the research participants or whether they are aware of any reading strategy in accomplishing their reading tasks before moving on to the final stage of study which would be to describe to what extent the adaptation of the 5-Step Monroe's Motivated Sequence helps as a scaffold for the research participants in completing their reading assignments. Subsequently, thorough descriptions of how the adapted model of the 5-Step Monroe's Motivated Sequence can aid in developing reading behaviors in the research participants would then be provided. Strategic techniques which can create conducive and effective learning need to be identified in order to motivate the aspirants during their formation years. It is hoped that the outcome of the proposed actual study could provide the foundation needed by the Formation House, Catholic Archdiocesan Centre in providing the most meaningful avenue for classroom activities for the development of reading behaviors and most importantly to consequently inculcate the love for reading among the research participants and other future aspirants. A simple yet conscientiously designed language activity which uses the adapted 5-Step Monroe's Motivated Sequence may provide the solution to curb the problem of low reading habits among aspirants and to inspire unmotivated learners who dislike reading in general. It is hoped that the adaptation of the 5-Step Monroe's Motivated Sequence could be proven to be helpful in steering fellow aspirants to become proficient in using the English language and consequently become articulate in sharing their knowledge and ideas particularly in an 
academic setting and in their job as priests in future. The adaptation of this model as the scaffolding for reading activities would become the basis for the development of a holistic ESL learning module which may be used not only for classroom settings at the Formation House, Catholic Archdiocesan Centre, Kota Kinabalu, Malaysia but also in other ESL classroom settings which aim to prepare their students to achieve desirable results in any examination or assessment involving the use of the English language. A concept of the phenomena on how a certain level of learning occurred where the 5-Step Monroe's Motivated Sequence was used as a scaffold and how the integration of the reading assignments with the verbal presentations could help to a certain extent in the reading development of the research

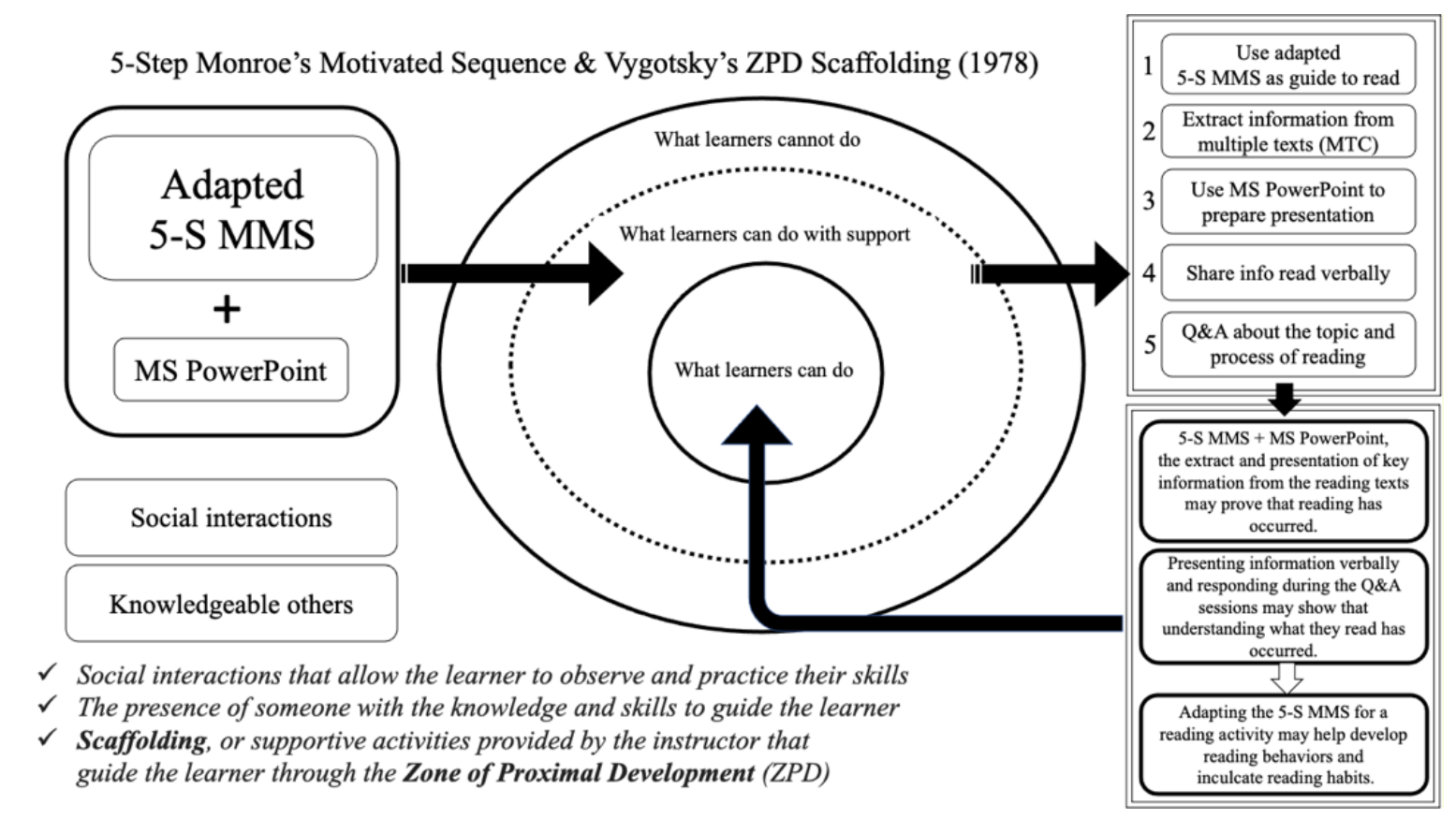

participants is shown is Figure 3.

Figure 2. A concept of phenomena on 5-Step Monroe's Motivated Sequence \& Vygotsky's ZPD Scaffolding (1978)

\section{Limitations and Future Research}

Although the researcher was given a written consent to conduct the preliminary study and was given full access to the population of interest to the study as well as unlimited visits to the setting of the investigations, the study was confined to a very specific group of research participants which may not have allowed vigorous investigations on whether using the model as a scaffold in reading behavior development would help other ESL readers in a different setting or context. In addition, since the research participants were all adult males, the findings of the study could not represent the diverse groups of ESL readers according to gender and age and therefore, the use of the model in other research settings may have distinct observations and outcomes. However, this was inevitable and was out of the researcher's control since the organization who provided the funding for this study had specifically requested that the investigation should directly involve the aspirants and should revolve around the fields of their studies particularly in English language learning at the Formation House. The study may however be replicated for future research involving other groups of research participants. Another concern was that the researcher had to concurrently 
conduct the investigation and be the language instructor at the Formation House throughout the study. This may raise the issues of reliability of the processes and procedures of the investigation as well as the validity of the findings and results of the investigation. However, usually in cases where the scenario is as such, it is imperative that the rapport between the researcher and the research participants be one that exudes supportive learning environments and which is non-threatening for the research participants to feel compelled to provide their responses and input throughout the process of data collection. Apart from that, though data collection was done involving the whole population of the Year 2 Aspirants for this preliminary study, the analysis of collected data and the reporting of findings were done as a collective whole. The proposed actual study may involve more vigorous data collection to reach data saturation while data analysis could be done systematically by utilizing data management software like ATLAS.ti. In addition, a thorough description of the lived experiences of the research participants should be done for each research participant as a unique individual in order to identify, describe and report salient features in the findings for examples like how Blyseth (2015) and Romick (2020). Upon completion of the study, opportunities to conduct related studies may include an investigation on the effectiveness of the adapted version of the 5-Step Monroe's Motivated Sequence as a scaffold in reading development. It may be used as an intervention in either true experimental or quasiexperimental research design and could be done with either a smaller or a bigger sample size of research participants. Apart from that, development and designing of a general holistic learning module or a target-specific syllabus design that will integrate the four language skills can be done. This could lead to productions and publications of innovative learning modules for English.

\section{Conclusion}

Generally, this preliminary study concluded that the 5-Step Monroe's Motivated Sequence gave the participants the push factor to read in order to be more ready in presenting ideas and in sharing their newly-acquired knowledge using the English language. The learning activities which involved searching for, selecting and reading various information to fulfil the five steps before the research participants did classroom verbal presentations was found to be an exhilarating and fulfilling learning process for them although a certain level of stress caused by external factors was felt by the research participants. Using the 5-Step Monroe's Motivated Sequence as a scaffold for reading had also made the research participants become more responsible in their learning and, most importantly, the understanding of issues as well as the retention of knowledge gained through the reading tasks were observed during the class presentations. However, the research participants needed more guidance by the instructor in understanding the five steps involved in Monroe's Motivated Sequence. Without proper instructions and modelling the scaffold, the research participants would not be able to effectively accomplish the reading tasks and hence, would not be able to exhibit articulate, analytical and critical minds during their presentations. This preliminary study achieved its aim at determining the feasibility of using the 5-Step Monroe's Motivated Sequence for a reading activity. Insights on what needs to be modified in the model or added in the research procedure were also noted to improve the proposed actual study in order to explore the full potential the 5-Step Monroe's Motivated Sequence to be used as a scaffold for reading development. It is hoped that using the 5-Step Monroe's Motivated Sequence as a scaffold in a reading activity would provide strategic techniques for ESL learners to develop their reading behaviors so that they may have a paradigm shift from being unmotivated readers to avid 
readers and later become skilled readers who are capable of transferring newly-acquired knowledge with eloquence through verbal presentations.

\section{Funding}

This study was supported by the Catholic Archdiocese of Kota Kinabalu, Malaysia as a project meant for the enrichment of English classroom activities for the aspirants at the Formation House. A project report was written to document necessary improvement for an actual PhD study and to disseminate the findings of the study to a professional audience.

\section{Acknowledgements}

We thank the Archbishop of Kota Kinabalu for funding this project and for giving consent to conduct the study with full access to the Formation House throughout the study. We also wish to thank the priest in-charge of the aspirants for his time and contribution of ideas to improve the research plan. Finally, we thank the aspirants for their great participation throughout the study.

\section{References}

Afflerbach, P., Pearson, P. D., \& Paris, S. G. (2008). Clarifying differences between reading skills and reading strategies. The Reading Teacher 61(5): 364-373. International Reading Association

Ahmadi, M. R., Ismail, H. N., \& Abdullah, M. K. K. (2013). The importance of metacognitive reading strategy awareness in reading comprehension. English Language Teaching 6(10): 235-244. Canadian Center of Science and

Education. http://dx.doi.org/10.5539/elt.v6n10p235

Ahmed, S. (2016). Reading habits and attitudes of UMSKAL undergraduates. International Journal of Applied Linguistics and English Literature 5(2): 189-201. Australian International Academic Centre. http://dx.doi.org/10.7575/aiac.ijalel.v.5n.2p.189

Annamalai, S., \& Muniandy, B. (2013). Reading habit and attitude among Malaysian polytechnic students. International Online Journal of Educational Sciences 5(1): 3241. http://www.iojes.net/userfiles/article/iojes_946.pdf

Baba, J., \& Affendi, R. F. (2020). Reading habit and students' attitudes towards reading: A study of students in the Faculty of Education UiTM Puncak Alam. Asian Journal of University Education 16(1): 109-122. http://doi.org/10.24191/ajue.v16i1.8988

Beek, M. T., Opdenakker, M. C., Spijkerboer, A. W., Brummer, L., Ozinga, H. W., \& Strijbos, J. W. (2019). Scaffolding expository history text reading: Effects on adolescents' comprehension, self-regulation, and motivation. Learning and Individual Differences 74 (101749). Elsevier Inc. https://doi.org/10.1016/j.lindif.2019.06.003

Belzer, A. (2002). "I don't crave to read": School reading and adulthood. Journal of Adolescent \& Adult Literacy 46(2): 104-113. http://doi.org/10.1598/jaal.46.2.2

Blyseth, A. R. (2015). A phenomenological study of adult reading motivation. PhD Thesis. Retrieved from ProQuest Dissertations and Theses.

Brevik, L. M. (2019). Explicit reading strategy instruction or daily use of strategies? Studying the teaching of reading comprehension through naturalistic classroom observation in English L2. Reading and Writing. Springer Netherlands. https://doi.org/10.1007/s11145-019-09951-w

Chiang, M. (2015). Effects of varying text difficulty levels on second language (L2) reading attitudes and reading comprehension. Journal of Research in Reading 39(4): 1-21. 
Chien, C. C., \& Yu, K. (2015). Applying extensive reading to improve unmotivated learners' attitudes toward reading in English. International Journal of Learning, Teaching and Educational Research 13(2).

Cho, B. (2013). Adolescents' constructively responsive reading strategy use in a critical internet reading task. Reading Research Quarterly 48(4): 329-332. International Reading Association. http://doi.org/10.1002/rrq.49

Coiro, J. (2011). Predicting reading comprehension on the Internet: Contributions of offline reading skills, online reading skills, and prior knowledge. Journal of Literacy Research 43(4): 352-392.

Creswell, W. J., \& Poth, N. P. (2018). Qualitative inquiry \& research design: Choosing among five approaches ( $\left.4^{\text {th }} \mathrm{Ed}\right)$. SAGE Publications Inc: California.

Dobzyniak, R. A. (2020). Einstein kindergarteners: A basic qualitative study on scaffolding strategies in reading. PhD Thesis. Retrieved from ProQuest Dissertations and Theses.

Doležalová, J. (2017). Development of interest in reading on the part of students and future academics. Acta Educationis Generalis 7(3): 9-24.

Dollinger, S. J. (2016). "You are as you read": Do students' reading interests contribute to their individuality? Reading Psychology 37:1-26. Routledge Taylor \& Francis Group. http://doi.org/10.1080/02702711.2014.966184

Gibbons, P. (2015). Scaffolding language. Scaffolding learning: Teaching English language learners in the mainstream classroom $\left(2^{\text {nd }} E d\right)$. Heinemann: Portsmouth.

Gros, B., \& Lopez, M. (2016). Students as co-creators of technology-rich learning activities in higher education. International Journal of Educational Technology 13 (28). Springer International Publishing. http://dx.doi.org/10.1186/s41239-016-0026-x

Guthrie, J. T., \& Wigfield, A. (2000). Engagement and Motivation in Reading. In M. L. Kamil, P. B. Mosenthal, P. D. Pearson, \& R. Barr (Eds.). Handbook of Reading Research (3rd ed.). New York, NY: Longman.

Hamidi, E., \& Bagherzadeh, R. (2018). The logical problem of scaffolding in second language acquisition. Asian-Pacific Journal of Second and Foreign Language Education 3:19. https://doi.org/10.1186/s40862-018-0059-x

Haugen, J., \& Lucas, K. (2019). Unify and present: Using Monroe's Motivated Sequence to teach team presentation skills. Communication Teacher. 33(2): 112-116.

Hautala, J., Loberg, O., Azaiez, N., Taskinen, S., Tiffin-Richards, S. P., \& Leppänen, P. H. T. (2019). What information should I look for again? Attentional difficulties distracts reading of task assignments. Learning and Individual Differences. 75(101775). https://doi.org/10.1016/j.lindif.2019.101775

Heng, C. S. (2012). Defining English language proficiency for Malaysia tertiary education: Past, present and future efforts. Advances in Language and Literacy Studies 3(2): 150-160.

Jamshidifarsani, H., Garbaya, S., Lim, T., Blazevic, R., \& Ritchie, J. M. (2019). Technology-based reading intervention programs for elementary grades: An analytical review. Computers \& Education 128: 427-451. Elsevier

Ltd. https://doi.org/10.1016/j.compedu.2018.10.003

Jensen, M. T., Solheim, O. J., \& Idsoe, E. M. C. (2019). Do you read me? Associations between perceived teacher emotional support, reader self-concept, and reading achievement. Social Psychology of Education 22: 247-266. Springer International Publishing. https://doi.org/10.1007/s11218-018-9475-5 
Karim, N. S. A., \& Hasan, A. (2007). Reading habits and attitude in the digital age: Analysis of gender and academic program differences in Malaysia. The Electronic Library 25(3): 286298. http://doi.org/10.1108/02640470710754805

Knowles, M. S., Holton III, E. F., \& Swanson, R. A. (2005). The adult learner: The definitive classic in adult education and human resource development $\left(6^{\text {th }} \mathrm{Ed}\right)$. Elsevier Inc: London.

Kung, F. W. (2019). Teaching second language reading comprehension: the effects of classroom materials and reading strategy use. Innovation in Language Learning and Teaching 13(1): 93-104. Routledge Taylor and Francis

Group. http://doi.org/10.1080/17501229.2017.1364252

Kurt, S. (2020). "Vygotsky's Zone of Proximal Development and scaffolding," in Educational Technology, https://educationaltechnology.net/vygotskys-zone-of-proximaldevelopment-and-scaffolding

Latini, N., Braten, I., Anmarkrud, O., \& Salmeron, L. (2019). Investigating effects of reading medium and reading purpose on behavioral engagement and textual integration in a multiple text context. Contemporary Educational Psychology 59 (101797). Elsevier Inc. https://doi.org/10.1016/j.cedpsych.2019.101797

Lee, H. G. (2012). ESL learners' motivation and task engagement in technology enhanced language learning contexts. PhD Thesis. Retrieved from ProQuest Dissertations and Theses.

List, A., \& Alexander, P. A. (2017). Analyzing and integrating models of multiple text comprehension. Educational Psychologist. 52(3):143-147. http://doi.org/10.1080/00461520.2017.1328309

Liu, Z. (2005). Reading behavior in the digital environment: Changes in reading behavior over the past ten years. Journal of Documentation 61(6): 700-712. Retrieved from http://www.emeraldinsight.com

Liu, Z., \& Huang, X. (2016). Reading on the move: A study of reading behavior of undergraduate smartphone users in China. Library and Information Science Research 38: 235-242. Elsevier Inc. http://dx.doi.org/10.1016/j.lisr.2016.08.007

Lucas, S. E. (2015). The Art of Public Speaking.12 ${ }^{\text {th }}$ Ed. (pp321-323). McGraw-Hill Education: New York.

Matterson, C. A. (2015). Why Johnny can read: Second grade teachers' perceptions of the best practices in literacy instruction. PhD Thesis. Retrieved from ProQuest Dissertations and Theses.

McDermott, V. M. (2004). Using Motivate Sequence in persuasive speaking: The speech for charity. Communication Teacher 18(1): 13-14.

Metsäpelto, R. L., Silinskas, G., Kiuru, N., Poikkeus, A. M., Pakarinen, E., Vasalampi, K., Lerkkanen, M. K., \& Nurmi, J. E. (2017). Externalizing behavior problems and interest in reading as predictors of later reading skills and educational aspirations. Contemporary Educational Psychology 49: 324-336. Elsevier Inc. http://doi.org/10.1016/j.cedpsych.2017.03.009

Mizrachi, D. (2015). Undergraduates' academic reading format preferences and behaviors. The Journal of Academic Librarianship 41: 301-311. Elsevier Ltd. Retrieved from http://www.sciencedirect.com

Mokhtari, K., \& Sheorey, R. (2002). Measuring ESL students' awareness of reading strategies. Journal of Developmental Education 25(3): 2-10. 
Morefield, V. M. (2013). Literacy that matters: How teachers' instructional decisions shape students' reading identities and learning outcomes. PhD Thesis. Retrieved from ProQuest Dissertations and Theses

Moustakas, C. (1994). Phenomenological research methods. SAGE Publications Ltd: California. Muijselaar, M. M. L., Swart, N. M., Steenbeek-Planting, E. G., Droop, M., Verhoeven, L., \& de Jong, P. F. (2017). Developmental relations between reading comprehension and reading strategies. Scientific Studies of Reading 21(3): 194209. https://doi.org/10.1080/10888438.2017.1278763

Mulumba, M. B. (2016). Enhancing the reading culture among language education graduate students through emerging technologies. Technology, Innovation and Education 2(6): Springer International Publishing.

Netten, A., Droop, M., \& Verhoeven, L. (2011). Predictors of reading literacy for first and second language learners. Reading and Writing 24(4) :413-425. https://doi.org/10.1007/s11145-010-9234-2

Niazifar, A., \& Shakibaei, G. (2019). Effects of different text difficulty levels on Iranian EFL learners' foreign language reading motivation and reading comprehension. AsianPacific Journal of Second and Foreign Language Education 4(7). https://doi.org/10.1186/s40862-019-0070-x

Nonte, S., Hartwich, L., \& Willems, A. S. (2018). Promoting reading attitudes of girls and boys: a new challenge for educational policy? Multi-group analyses across four European countries. Large-scale Assessments in Education 6(5). Springer International Publishing. https://doi.org/10.1186/s40536-018-0057-y

Parvis, E. (2020). How to survive a zombie apocalypse: Using Monroe's Motivated Sequence to persuade in a public-speaking classroom. Communication Teacher 34(1). http://doi.org/10.10.1080/17404622.2019.1608370

Peavy, J. (2018). A qualitative study of reading comprehension and high school graduates in transition to employment in the U.S. Rural Southeast Alabama. PhD Thesis. Retrieved from ProQuest Dissertations and Theses.

Pew Research Center. (2019). "The Digital Pulpit: A nationwide analysis of online sermons." http://www.pewresearch.org

Pfost, M., Dorfler, T., \& Artelt, C. (2013). Students' extracurricular reading behavior and the development of vocabulary and reading comprehension. Learning and Individual Differences 26: 89-102. http://dx.doi.org/10.1016/j.lindif.2013.04.008

Putro, N. H. P. S., \& Lee, J. (2018). Profiles of readers in a digital age. Reading Psychology 39: 585-601. https://doi.org/10.1080/02702711.2018.1496502

Qiufeng, G., Huan, W., Di, M., Yaojiang, S., Kenny, K. \& Rozelle, S. (2018). Can reading programs improve reading skills and academic performance in rural China? China Economic Review 52:111-125. https://doi.org/10.1016/j.chieco.2018.07.001

Ramiza, D., \& Albion, P. (2013). English language in Malaysian education system: Its existence and implication. Paper presented at $3^{\text {rd }}$ Malaysian Postgraduate Conference (MPC2013), Sydney, New South Wales, Australia.

Robinson, J. L. (2010). English language learners' motivation to engage in reading. PhD Thesis. Retrieved from ProQuest Dissertations and Theses.

Romick, M. J. (2020). The lived experiences of high-school students who self-identify as readers: A phenomenological study. PhD Thesis. Retrieved from ProQuest Dissertations and Theses. 
Rupley, W. H., Blair, T. R., \& Nichols W. D. (2009). Effective reading instruction for struggling readers: The role of direct/explicit teaching. Reading \& Writing Quarterly 25: 125138. http://dx.doi.org/10.1080/10573560802683523

Salem, A. A. M. S. (2016). Scaffolding reading comprehension skills. English Language Teaching 10 (1): 97-111. Canadian Center of Science and Education.

Sharmin, A., \& Lutfeali, S. (2017). A journey to reading hub: A repository of Bangla reading skill development through technology. Systemics, Cybernetics and Informatics 15(4): $97-$ 102.

Sloan, A. \& Bowe, B. (2014). Phenomenological and hermeneutic phenomenology: the philosophy, the methodologies and using hermeneutic phenomenology to investigate lecturers' experiences of curriculum design. Quality \& Quantity 48(3): 1291-1303.

Soler, J. (2017). The politics of teaching reading. Prospects 46: 423-433. https://doi.org/10.1007/s11125-017-9415-8

Van Rijk, Y., Volman, M., de Haan, D., \& van Oers, B. (2017). Maximising meaning: creating a learning environment for reading comprehension of informative texts from a Vygotskian perspective. Learning Environments Research 20: 77-98. Springer Netherlands. http://doi.org/10.1007/s10984-016-9218-5

Vela, V. (2015). Using glosses for incidental vocabulary acquisition. Procedia - Social and Behavioral Sciences. 199 (2015) 305-310.

Wilson, K. (2016). Critical reading, critical thinking: Delicate scaffolding in English for Academic Purposes (EAP). Thinking Skills and Creativity 22: 256-265. Retrieved from http://www.elsevier.com/locate/tsc

Wu, L., Valcke, M., \& Van Keer, H. (2019). Factors associated with reading comprehension of secondary school students. Educational Sciences: Theory and Practice 19(4), 34 - 47. http://dx.doi.org/10.12738/estp.2019.4.003

Zainab, M. N., Isarji, S., \& Zaidi, M. A. (2017). English language proficiency and initiatives of Malaysian universities. The Social Sciences 12(1): 1-4.

Zhang, L. J. (2007). Constructivist pedagogy in strategic reading instruction: exploring pathways to learner development in the English as a second language (ESL) classroom. Instructional Science (2008) 36:89-116. http://doi.org/10.1007/s11251-007-9025-6

Zimmerman, B. J. (2008). Investigating self-regulation and motivation: Historical background, methodological developments, and future prospects. American Educational Research Journal 45(1): 166-183. https://doi.org/10.3102/0002831207312909 